\title{
The Next-in-Line Effect
}

\author{
MALCOLM BRENNER ${ }^{1}$ \\ University of Michigan, Ann Arbor, Michigan 48104
}

\begin{abstract}
Subjects performed a free recall task while seated in a square. One by one, alternate subjects exposed a word card and read the word out loud to the group. The remaining subjects simply listened. All subjects were tested for recall. Subjects who performed tended not to recall words read $9 \mathrm{sec}$ before and after their performance ("scallop effect"), and this loss increased with performance difficulty. Incidental evidence suggested high recall for material performed by particular subjects ("peak effects") and channel capacity. When subjects are next in line they may ignore cues not related to performing.
\end{abstract}

Being next in line to perform can have strong effects on a performer's attention. For example, the author finds that while he is waiting to ask a question in a large seminar, he is often unaware of anything else happening in the room. Even after asking the question, it may be difficult, at first, to pay attention to the answer. In a familiar encounter group exercise, members summarize the remarks of the previous speaker before they are allowed to begin their own comments, another acknowledgement that ready speakers may stop listening to the group.

The present paper attempts to establish the next-in-line phenomenon experimentally in a simple recall paradigm. Subjects in a grouprecall experiment were responsible for presenting the material, taking turns individually reading a single word out loud until an entire list was read. The experiment studied what happened to their recall as a result of this requirement, and particularly what happened when a subject changed from being a member of the audience into being a performer, and then returned to the audience.

\section{MeTHOD}

\section{Subjects}

The subjects were 88 male undergraduates in the University of Michigan, completing a psychology class requirement. This sample represented the first 22

${ }^{1}$ The author is indebted to Robert Zajone and Rick Crandall for their comments. This research was supported by an N.S.F. predoctoral fellowship. subjects to appear at each of four sessions, out of 113 scheduled. Almost all reported being strangers to the other subjects tested at their session.

\section{Procedure}

The room was arranged with tables set up in a large square, and chairs spaced in pairs on the outside of this square. Subject numbers were assigned consecutively around the square. At each subject's place were arranged a practice card and six numbered word cards, with a unique word typed on the face-down side of every card. For practice cards the words were low-association nonsense syllables (Hilgard, 1951) while for numbered cards the words were drawn from the 500 most common words in printed English (Thorndike \& Lorge, 1944, p. 267) excluding homonyms. Even-numbered subjects had words drawn randomly from the first part of the alphabet (A to L) while odd-numbered subjects had words drawn randomly from the second part. Twentytwo answer pads and pencils were scattered around the outside of the room on additional chairs. A separate table and chair were provided for the experimenter.

When 22 subjects arrived, they were ushered into the room and seated in pairs at the tables. Taperecorded instructions began:

Good morning. There are 22 of you here, and you will be run together as a group. We will go around the circle one by one and when it is your turn, turn over a card and read the word that is written on it out loud. Later I will ask you to try to remember all the words that are read.

After a practice trial, in which each subject consecutively read his practice card out loud, the subjects performed four reading trials with real words, which they were instructed to recall. Two manipulations were introduced:

Read-listen manipulation. Only the odd- or evennumbered subjects read words on a trial while the 
remaining subjects merely listened. Both groups were then tested for recall. In this way, one member of every subject pair acted as a listening control on each trial.

Difficulty-of-the-task manipulation. Subjects were allowed more time to perform on some trials than on others. A foghorn-like noise (produced by amplifying background noise in the tape recorder) sounded at 3sec intervals during the trial. Subjects performed during the silent periods between foghorns. In the difficult treatments the foghorn filled $1.7 \mathrm{sec}$ and left only 1.3 sec for performing. In the easy treatments it filled 0.2 $\mathrm{sec}$ and left $2.8 \mathrm{sec}$ to perform.

Odd- and even-numbered subjects performed on alternate trials, with the use of different halfs of the alphabet helping to reduce successive interference. Instructions announced the next-in-line subject number at the beginning of each turn. Subjects did not turn up cards until the beginning of their turns, returned the cards word-side down, and read a new card each time they were called. After 25 words the readings were stopped and all subjects were given $1.5 \mathrm{~min}$ to write as many of the words as they could recall. Ten seconds of instructions separated the performance and recall tasks to allow time to go to the pads, and to reduce recall for recent items. After four trials, subjects were given a full explanation of the experiment and the session was concluded.

\section{Overall Design and Counterbalancing}

There were four treatments: Read-Difficult task, Read-Easy task, Listen-Difficult task, and Listen-Easy task. In a within-subject design, subjects performed a different treatment on each trial. Four orders were employed: RD, LE, RE, LD; LD, RE, LE, RD; RE, LD, RD, LE; and LE, RD, LD, RE. Because of the read-listen manipulation, Orders 1 and 2 and Orders 3 and 4 were necessarily run at the same session, and the four sessions allowed for two replications of the orders with different lists. The square design helped counterbalance word-order effects and unusual performance effects by representing all positions simultaneously on each trial. Starting positions were varied for the practice, easy, and difficult trials and spaced at different parts of the square.

\section{RESULTS}

The first two words and the last word of each list were not analyzed to reduce serial order effects. The remaining 22 words represented two performances for every subject who performed. A performed word or its homonym were correct; plurals and alternative grammatical forms, incorrect.

Mean recall out of 22 words was similar for the four treatments: Read-Difficult, 5.59 words; Read-Easy, 6.35; Listen-Difficult, 6.16; Listen-Easy, 6.35. Several interesting trends appeared, however, when recall was plotted by position of the performance relative to the subject. These are shown in Figure 1. Numbers on the abcissa indicate how

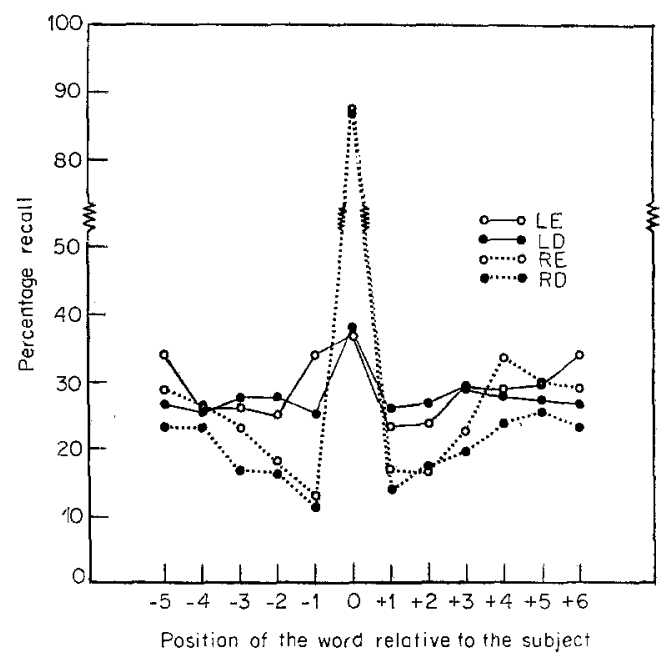

FIG. 1. Recall as a function of word input position for readers (R) and listeners (L) under difficult (D) and easy (E) pacing.

many pairs away from the subject the presented word took place, with -5 and +6 identical. First, subjects showed high recall for Position 0 words, recalling $87 \%$ of the words performed by themselves and $37 \%$ of those by their paired neighbor, $F(1,3440)=$ 623 for own words versus all other words, and $F(1,3440)=127$ for neighbor's words versus all other words. Second, performing subjects tended not to recall words read as many as three positions $(9 \mathrm{sec})$ before and after performance, $F(1,2160)=53.4$ for Read-versusListen, $p<.001$, with the loss nearly symmetrical and scallop shaped. Position effect, excluding Position 0 , was negligible in the Listen treatments, $F(9,720)=.70$, but highly significant in the Read treatments, $F(9,720)=$ 
$6.52, p<.001$. Finally, the difficulty of the task manipulation was significant for subjects who read, $F(1,2160)=9.49, p<.01$, but not for subjects who merely listened, $F(1,2160)=$ .79 .

An idealized model of the scallop effect shown in Figure 2 was constructed around the significant items in the analysis of variance and was used to find individual differences in scallop effect. Eighty-one subjects showed a positive effect. Surprisingly, there was no relationship between the strength of scallop effect and the recall of own words, $r=.04$, or of neighbor's words, $\mathrm{r}=.07$. present scallop is unusual in being the largest reported and one of the few cases of near symmetry. Previous literature has shown loss up to only $2 \mathrm{sec}$ before peak item (Tulving, 1969; Smith, 1949), a time period shorter than one interval in the present experiment.

The scallop can be explained as interference between two tasks. As a member of the audience and as a performer before the audience, the subject has incompatible demands on his attention. The scallop would occur because he attends to performance cues at the expense of other available cues including the cues (words) measured in the experiment.

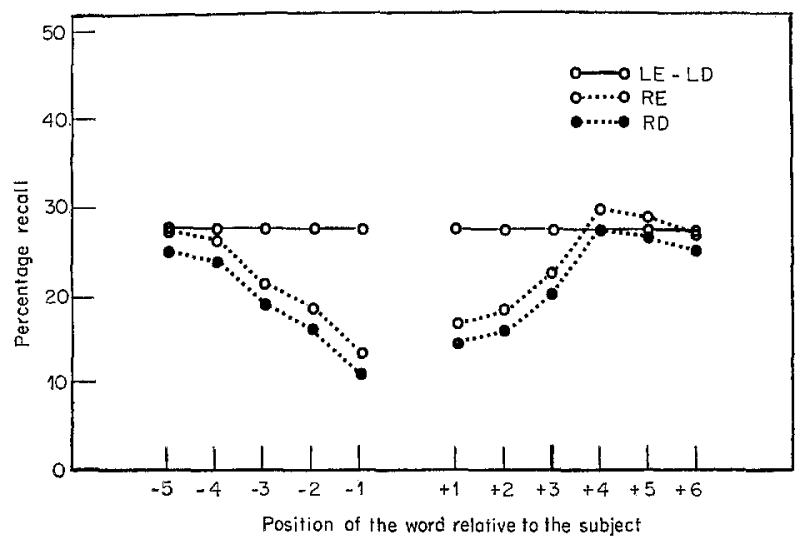

FIG. 2. A model of the scallop effect derived from the analysis.

\section{DISCUSSION}

The experiment concerned one effect but concluded with two. Consistent with the nextin-line prediction, subjects tended not to recall material performed $9 \mathrm{sec}$ before and after their own performance (the scallop effect), and loss increased with performance difficulty. In addition, subjects showed a high recall for material performed by themselves and their immediate neighbors (partners) that was independent of scallop losses. Similar peak and scallop effects have been reported in the literature on retrograde amnesia (Tulving, 1969; Saufley \& Winograd, 1970; Schulz, 1971) and von Restorff effects (Jenkins \& Postman, 1948; Smith, 1949), although the
This shift should begin the moment the subject perceives being next in line, perhaps 9 or $7 \mathrm{sec}$ (including retrograde loss) before performing, and from this moment he stops attending to words except as cues to begin his own performance. The unusual second half of the scallop is more difficult to interpret. At least it demonstrates that time is required to return attention to the competing task, perhaps because arousal is involved. If arousal acts as a mediating variable, as suggested by several sources (Zajonc, 1965; Mandler \& Sarason, 1952; Paivio, 1965), the process would be parallel to those described by Easterbrook (1959) and Deutsch and Deutsch (1963). Actual memory loss might occur at any stage, but probably occurs in coding from 
short-term to long-term memory (Murdock, 1965; Broadbent \& Heron, 1962).

It is necessary for the next-in-line interpretation to demonstrate that performance demands alone could not cause the results. Simply turning up cards can interfere with subsequent recall (e.g., Murdock, 1965), and loss might occur because of temporal proximity rather than any next-in-line readiness. The fact that the scallop is larger than demonstrated retrograde effects helps argue this case, as do the wide individual differences and the second half of the scallop. But the case is strongly supported by a recent follow-up with dating couples showing effects without actual performance. ${ }^{2}$ Subjects show a vicarious peak and scallop when someone they are dating performs, with the size of the effects a predictor of the likelihood of their remaining together.

The peak effect can be partly explained by the extra motor, visual, and auditory cues available for recall from when the subject performs. However, the size of the peak, peak for the neighbor, and the vicarious peak effect ${ }^{2}$ indicate a motivational element as well in which subjects recall to the extent that they are interested in the performer. Neighbors would qualify simply by proximity.

Finally, it is interesting that recall in all treatments was nearly identical despite the high peak recall when the subject himself was the reader. This incidental finding appears regularly in retrograde amnesia data and von Restorff data as well, and suggests a memory ceiling where large peak recall is offset by general losses throughout the serial order curve.

The requirement to perform, then, can strongly influence a subject's use of available

${ }^{2}$ Brenner, M. Caring, love, and selective memory. Manuscript under editorial review. information. Even college students in a minor task may be subject to a next-in-line fear when performing before others.

\section{REFERENCES}

Broadbent, D. E., \& Heron, A. Effects of a subsidiary task on performance involving immediate memory by younger and older.men. British Journal of Psychology, 1962, 53, 189-198.

Deutsch, J. A., \& Deutsch, D. Attention: Some theoretical conditions. Psychological Review, $1963,70,80-90$.

EASTERBrook, J. A. Effects of emotion on cue utilization and organization of behaviour. Physchological Review, 1959, 66, 183-198.

HilgaRd, E. R. Methods and procedures in the study of learning. In S. S. Stevens (Ed.), Handbook of experimental psychology. New York: Wiley, 1951.

Jenkins, S. O., \& Postman, L. Isolation and "spread of effect" in serial learning. American Journal of Psychology, 1948, 61, 214-221.

Mandler, G., \& Sarason, S. B. A study of anxiety and learning. Journal of Abnormal and Social Psychology, 1952, 47, 166-173.

MuRDOCK, B. B. Effects of a subsidiary task on shortterm-memory. British Journal of Psychology, 1965 , $56,413-421$.

PaIvio, A. Personality and audience influence. In B. Maher (Ed.), Progress in experimental personality research, Vol. 2. New York: Academic Press, 1965.

SAUfley, W. H., \& WinOGRad, E. Retrograde amnesia and priority instructions in free recall. Journal of Experimental Psychology, 1970, 85, 150-152.

ScHulz, L. S. Effects of high-priority events on recall and recognition of other events. Journal of Verbal Learning and Verbal Behavior, 1971, 10, 322-330.

SMITH, M. The influence of isolation on immediate memory. American Journal of Psychology, 1949, 62, 405-411.

THORNDIKE, E. L., \& LORGE, I. The teacher's word book of 30,000 words. New York: Bureau of Publications, Teacher's College, Columbia University, 1944.

TuLVING, E. Retrograde amnesia in free recall. Science, 1969, 164, 88-90.

ZAJONC, R. B. Social facilitation. Science, 1965, 149, 269-274.

(Received January 9, 1973) 